The University of Maine

DigitalCommons@UMaine

University of Maine Office of Research and

Sponsored Programs: Grant Reports

Special Collections

6-15-2001

\title{
A Multimedia Based Laboratory Course for Environmental Engineering Fundamentals and Process Design
}

Lynn E. Katz

Principal Investigator; University of Maine, Orono

Lenly Weathers

Co-Principal Investigator; University of Maine, Orono

Follow this and additional works at: https://digitalcommons.library.umaine.edu/orsp_reports

Part of the Curriculum and Instruction Commons, and the Environmental Engineering $\underline{\text { Commons }}$

\section{Recommended Citation}

Katz, Lynn E. and Weathers, Lenly, "A Multimedia Based Laboratory Course for Environmental Engineering Fundamentals and Process Design" (2001). University of Maine Office of Research and Sponsored Programs: Grant Reports. 214.

https://digitalcommons.library.umaine.edu/orsp_reports/214 
Final Report for Period: 03/1997 - 02/2000

Principal Investigator: Katz, Lynn E.

Organization: University of Maine

Title:

A Multimedia Based Laboratory Course for Environmental

Senior Personnel

Name: Katz, Lynn

Worked for more than 160 Hours: Yes

Contribution to Project:

Name: Weathers, Lenly

Worked for more than 160 Hours: Yes

Contribution to Project:

Name: Scott, Mike

Worked for more than 160 Hours: Yes

Contribution to Project:

Director of ASAP Media Services
Submitted on: 06/15/2001

Award ID: 9653149

Engineering Fundamentals and Process Design

Project Participants

\section{Post-doc}

\section{Graduate Student}

Name: Kozlowski, Ronald

Worked for more than 160 Hours: Yes

Contribution to Project:

Project Manager

Technical Programmer/Designer on Experiment Modules

Name: Austin, Kevin

Worked for more than 160 Hours: Yes

Contribution to Project:

Content Advisor

Name: Arsenalut, Joe

Worked for more than 160 Hours: Yes

Contribution to Project:

\section{Undergraduate Student}

Name: Treadwell, Darin

Worked for more than 160 Hours: Yes

Contribution to Project:

Content Driector

Name: Genz, Ryan

Worked for more than 160 Hours: Yes

Contribution to Project:

Art Director

UI Designer 
Name: Farrington, Jay

Worked for more than 160 Hours: Yes

Contribution to Project:

Art Director

Name: Dority, Gavin

Worked for more than 160 Hours: Yes

Contribution to Project:

Chief HTML/Java Script Programmer

Name: Faatz, Justin

Worked for more than 160 Hours: Yes

Contribution to Project:

Audio/Video Director

Content Developer

Name: Frank, Chris

Worked for more than 160 Hours: Yes

Contribution to Project:

Programmer

Name: Goodwin, Ryan

Worked for more than 160 Hours: Yes

Contribution to Project:

Dynamic Flash Content Developer

Name: Ebert, Erin

Worked for more than 160 Hours: Yes

Contribution to Project:

Programmer

Name: Maskey, Vishesh

Worked for more than 160 Hours: Yes

Contribution to Project:

Dynamic Content Programmer

Name: Harding, Ajay

Worked for more than 160 Hours: Yes

Contribution to Project:

HTML Programmer

Name: Roberts, Peter

Worked for more than 160 Hours: Yes Contribution to Project:

Flash developer

Name: Corbett, Patrick

Worked for more than 160 Hours: Yes

Contribution to Project:

Dyanmic Content developer

Name: Hamm, Andy

Worked for more than 160 Hours: Yes

Contribution to Project:

Artist

Name: Burke, Lindsay 
Worked for more than 160 Hours: Yes

Contribution to Project:

content

Name: Hernandez, Luis

Worked for more than 160 Hours: Yes

Contribution to Project:

dynamic content programmer

\title{
Research Experience for Undergraduates
}

\section{Organizational Partners}

\section{Other Collaborators or Contacts}

\author{
ASAP Media Services \\ 4th Floor Chadbourne Hall \\ University of Maine \\ Orono Me 04469
}

ASAP is a student run Multimedia organization

Directed by Mike Scott

\section{Activities and Findings}

\section{Project Activities and Findings:}

This grant focused on the development of interactive multi-media laboratory modules for a laboratory course in environmental engineering process dynamics. The goal of the laboratory component of the course is to allow students to acquire familiarity with the procedures for obtaining and determining design parameters for full scale systems from laboratory testing. The courseware is intended to enhance the laboratory experience by ensuring that students have a firm grasp of fundamental concepts and experimental methods for conducting process engineering laboratories. The course is divided into three major sections: environmental process flow dynamics, chemical reaction kinetics, and partitioning of contaminants between air/water, soil/water and organic/water systems. A laboratory component devoted to each major topic demonstrates how parameters used to describe contaminant transport are estimated in the laboratory and used in the field.

Multi-media modules were developed for the major topics in the course. The modules are designed to teach students how to collect, analyze and interpret data to obtain design parameters for engineered processes or mathematical modeling of contaminant transport in the environment. Each module contains concept, laboratory and analysis tutorials, videos of each lab, and an animated laboratory that can be used to: 1) acquire visual and conceptual familiarity with the experiment and determine sampling times and data requirements prior to the physical laboratory; and 2) evaluate the effects of design parameters after conducting the physical laboratory. The benefits of these modules include improving data quality obtained in the laboratory, enhancing understanding of key concepts, and establishing better linkage between theory and application.

\section{Project Training and Development:}

We completed beta versions of four major laboratories: Ideal Reactor Tracer Study, Non-Ideal Reactor Theory, Kinetics of Iron Oxidation and Kinetics of Biodegradation using Director (Macromedia, Inc.), Quicktime videos and Flash (Macromedia, Inc.). Each of these multimedia laboratories contains animated laboratories for different types of reactor systems (e.g. batch, completely mixed flow, and plug flow reactors). The beta version of these laboratories was reviewed by a number of professors and we are continuing to revise the laboratories to accomodate these recommendations.

\section{Research Training:}

This project was used to train a number of students from a range of disciplines on the development of multimedia software. ASAP Media Service, a student run organization at the University of Maine, is a learning, teaching, producing collaborative environment and was the focal point for student training. ASAP seeks projects that challenge the limits of technology use for educational and other communications purposes. This project was one of their strongest examples of successful collaborations with faculty across campus. Many people including undergraduate students, graduate students, faculty and professional employees, worked together to create a dynamic and truly interactive multimedia environment, where the user can interact with onscreen parameters to make changes and see results that otherwise could only be in a laboratory setting. Students who worked on the project had to learn technologies such as HTML, Flash, Flash Generator, Java Script, Cold Fusion, 
Quicktime, Director, and Photoshop. In addition, they had to learn how to coordinate their activities with students and staff working on other aspects of the project. The work conducted at ASAP was managed by students who participated in the project.

This project greatly affected the work of ASAP from a

development standpoint. The lessons learned have steered ASAP Media Service towards exploring more dynamic methods of producing and delivering content via the web. The time needed to construct an entire site produces challenges to repackaging and replication. Studying the project's reusable engine, how it was developed by combining a strong backend information system with a state-of-the-art graphical interface, using tools such as CVG, Flash Generator, and Swift, along with Macromedia Director and Flash, provokes new ideas about design with an eye for modularity and recyclability. ASAP has been able to continue to obtain projects to sustain this type of work, work that fosters research strategies for developing more easily adapted, replicable structures.

This project is used as the basis for most of the work in which ASAP Media Service is engaged. This project allowed the student developers to gain a greater understanding of the technologies that are required to create a dyanmic web based course. It also provided a greater understanding of how a student will interact with an educational web site. This interaction gave insight as to how one should construct an instructional, interactive web site that will enhance the learning process.

\section{Outreach Activities:}

In addition to the development of the multimedia software, this project has been used numerous times to demonstrate the level of true interactive learning experience possible for distance education. The advanced nature of its development has allowed us to utilize it consistently over the years. It serves as a basis for demonstrating true interactivity in contrast to today's standard of web interactivity.

ASAP Media Service has made a number of presentations involving the Civil project, including at University of Sheffield, England (1999), The 2000 Berlin Conference on Distance Education (fall 2000), Apple's ICamp (California, 2000), as well as numerous other presentations in the past two years, such as at UMass, Boston (2000), in Washington state (1999) and throughout Maine (1999-2001). This project has become a key component of these presentations. Indeed, any opportunity afforded ASAP Media Service to discuss the use of technology in education involves a discussion of this project.

In addition, the PIs have made a number of presentations at the American Society of Engineering Education Conference, the Frontiers in Education Conference and at the Association of Environmental Engineering and Science Professors Conference.

\section{Journal Publications}

\section{Books or Other One-time Publications}

Katz, L.E., L. Weathers, M. Scott, and R. Kozlowski,, "A Multimedia Based Laboratory in Environmental Engineering Fundamentals", (1998). CD-Rom, Published

Bibliography: Proceedings of the 1998 National ASEE Conference

\section{Web/Internet Site}

\section{URL(s):}

http://civil.asap.um.maine.edu/

http://homer.asap.um.maine.edu/civil/

\section{Description:}

http://civil.asap.um.maine.edu/ contains the complete project site.

http://homer.asap.um.maine.edu/civil/ is the site that is currently

being updated and tested do to feedback/testing that has

resulted from this project. Changes will include Dyanmic

Content and Quiz modules. Once the changes have been made

we will update 
http://civil.asap.um.maine.edu/ to reflect these new updates.

\section{Other Specific Products}

\section{Contributions within Discipline:}

\section{Contributions}

The materials developed in this project can be used by instructors in a range of courses in environmental engineering as either primary or secondary learning tools. The courseware was designed to serve as one of the primary learning tools for laboratory courses in environmental engineering process design. However, the modules can also be readily used in introductory environmental engineering courses, unit operations courses and biological and chemical treatment courses.

\section{Contributions to Other Disciplines:}

The principles demonstrated in the multimedia software developed in this project are also applicable to chemistry and chemical engineering courses in reactor theory and chemical kinetics.

\section{Contributions to Human Resource Development:}

In this project, undergraduate, graduate students and faculty contributed to the development of a multimedia laboratory based course that is available on the world wide web. The course is ideal for students who are unable to participate in actual laboratory courses and for distance learning. Many of the students who participated in this project have used the skills that they learned during this project to develop other multimedia software to promote distance and on-line learning.

\section{Contributions to Science and Technology Infrastructure:}

This project greatly affected work on a number of other multimedia projects. The lessons learned through the development of the courseware prepared for this project have led to other projects that use more dynamic methods of producing and delivering content via the web. The reusable engine produced in this project and the combination of a strong backend information system with a state-of-the-art graphical interface led to new ideas about web design that are being implemented in a number of other web-based projects at the University of Maine.

\section{Contributions: Beyond Science or Engineering:}

\section{Categories for which nothing is reported:}

\section{Organizational Partners}

Any Journal

Any Product

Contributions: Beyond Science or Engineering 